\title{
岫岩陨石坑：撞击起源的证据
}

陈鸣

(中国科学院广州地球化学研究所, 广州 510640. E-mail: mchen@gig.ac.cn)

\begin{abstract}
摘要 迄今为止, 世界上已发现 176 个陨石撞击坑. 对辽宁省岫岩满族自治县的一个环形构造的岩石冲 击效应、矿物变形微结构特征以及地貌特征等进行了研究. 该环形构造是一个直径 $1.8 \mathrm{~km}$ 、深 $150 \mathrm{~m}$ 的 碗状坑. 在坑内变形基岩石英颗粒中发现了击变面状页理(PDFs), 这是判断该坑陨石撞击起源的诊断 性标志. 坑区内冲击角砾岩和岩石震裂雉的产状, 以及撞击形成的地貌特征等均与陨石撞击作用结果 相符合. 这是中国第一个被证实的陨石撞击坑.
\end{abstract}

关键词 陨石撞击坑 冲击变质 击变面状页理 石英 岫岩

陨石坑是大的流星体、小行星或慧星撞击行星及 其卫星表面形成的一种特殊环状地质构造. 到目前 为止, 地球上已发现的陨石撞击坑数量为 176 个, 分 布在世界上 32 个国家(Earth Impact Database, 2007, http://www.unb.ca/passc/ImpactDatabase/index.html). 从 20 世纪 80 年代开始, 中国学者对中国的陨石坑开 展了系列的调查和研究, 找到了一批疑似陨石坑的环 状地质构造 [1 10]. 在国际陨石坑资料库中 (http://www. unb.ca/passc/ImpactDatabase/index.html), 中国版图上 陨石坑数目仍然为零. 中国陨石坑研究没有取得突 破的主要原因，是未能获得证实陨石撞击成因的关 键证据. 国际学术界将陨石撞击坑判别的诊断性标 准明确为撞击坑岩石造岩矿物石英和长石中发育击 变面状页理(planar deformation features, PDFs) ${ }^{[11 \sim 17]}$, 中国学者在过去研究中未曾报告这方面的证据.

位于辽宁省岫岩满族自治县苏子沟镇的一个环 形构造是中国学者曾经关注过的一个疑似陨石坑. 该坑地貌为一环形坑，当地居民称之为称为圈里. 20 世纪 70 年代初, 辽宁省地质局第一区测大队在本区 开展区域地质调查时将这一地质现象描述为旋涡状 构造. 1982 2004 年期间, 赵树明 ${ }^{[10]}$ 通过航空遥感地 质构造解译和实地观察, 推断该坑为陨石撞击形成. 1998 2001 年, 覃功畑等人 ${ }^{[9]}$ 通过地质填图和人工重 砂等样品分析, 也认为该坑形成与陨石撞击作用有 关. 然而, 过去的研究工作均没有取得坑区岩石和 矿物冲击变质的资料, 特别是缺失石英等矿物的击 变面状页理等关键证据, 该坑的陨石撞击成因未被 证实.
本文报道了对岫岩这个环形构造的岩石冲击效 应、矿物微结构特征、和其他地质地貌特征的初步研 究结果, 提供了陨石撞击作用的关键证据, 证实了该 坑的陨石撞击起源.

\section{1 地质和地貌概况}

本区地层为下元古界辽河群里尔峪组变质岩, 主要岩性为变粒岩、浅粒岩, 含少量大理岩和混合岩. 在坑区范围, 浅粒岩是主要岩性, 约含 $50 \mathrm{vol} \%(\mathrm{vol} \%$ 示体积百分，下同)石英、 $45 \mathrm{vol} \%$ 长石、 $4 \mathrm{vol} \%$ 云母、 少量角闪石、石榴子石、磷灰石、金红石等副矿物. 浅 粒岩中石英和长石粒度一般为 $1 \sim 5 \mathrm{~mm}$.

岫岩陨石撞击坑位于辽东半岛中部丘陵地带 $\left(40^{\circ} 21^{\prime} 55^{\prime \prime} \mathrm{N}, 123^{\circ} 27^{\prime} 34^{\prime \prime} \mathrm{E}\right)$, 在平面上呈现为近五边 形到似圆形. 该坑形态呈碗状(图 1), 直径为 $1.8 \mathrm{~km}$, 坑底与坑唇山脊高差为 $135 \sim 230 \mathrm{~m}$, 平均 $150 \mathrm{~m}$. 坑 底中央区海拔高度约 $140 \mathrm{~m}$.

坑唇山脊和坡地有厚度为 $0.5 \sim 6 \mathrm{~m}$ 的风化浮土. 坑底覆盖了较厚的泥岩和泥炭土等第四系湖沼相沉 积物. 坑唇坡地沟谷局部可见变形破碎基岩和角砾 岩出露. 坑的东北方向有个 $\mathrm{V}$ 形缺口, 沿着该缺口通 道可从坑外直接进入到坑内底部。整个坑区被小灌 木和庄稼等植被所覆盖.

\section{2 陨石撞击作用和岩石矿物冲击变质特征}

通过研究发现与撞击作用相关的特征包括：造 岩矿物石英中的冲击变形微结构, 岩石震裂雉, 与撞 
击过程和坑内岩石抛射相关的放射状沟谷地貌, 冲 击角砾岩等.

\section{1 石英中的击变面状页理}

经过对坑区岩石露头的系统采样和分析，在坑 底河沟出露的碎裂变形基岩(浅粒岩)中, 找到了发生 强烈变形的石英颗粒, 在其中发现了冲击作用产生 的面状页理(PDFs)(图 2), 其特征与著名的德国里斯 (Ries) 陨石坑石英击变面状页理相同 [11]. 在岩石薄片 上, 可观测到石英颗粒中的面状页理产生为类似片 晶状的结构, 片晶状薄片在石英颗粒中密集均匀分 布, 相邻薄片平行排列, 单个薄片厚度 $<1 \mu \mathrm{m}$, 薄片 间距 2 5 $\mu \mathrm{m}$. 通常在一个石英颗粒切面上可以观测到 $1 \sim 3$ 组薄片. 平行排列的薄片可以切穿整个石英颗粒, 也可以沿着晶体颗粒边缘局部发育. 在光学显微镜 上, 发育面状页理的石英颗粒干涉色一般比正常石 英偏低. 正交偏光下高放大倍数可以观测到平行排 列的片晶状结构实际上是由非均质与均质的薄片相
间排列而成. 非均质的薄片仍具有石英的晶体结构 特征, 而均质薄片发生了强烈变形甚至玻璃化.

\section{2 震裂雉}

震裂雉一般呈顶尖底圆的雉状岩块, 单个雉体 的大小为数厘米或更大, 雉面上布满了纵向的沟槽, 它是撞击作用形成的一种特殊类型的震裂构造. 我 们在坑唇的浅粒岩中, 找到了这种震裂雉. 图 3 展示 了一个震裂锥, 在它的圆雉面上有大量类似于擦痕 状的纵向沟槽. 这种规则和光滑的沟槽可以形成在 硬度较大的石英颗粒上. 在坚硬的浅粒岩中形成震 裂雉，表明冲击作用在岩石局部产生的极高的应力 状态, 导致局部滑动产生, 形成特殊纹理的雉面.

\section{3 冲击角砾岩}

坑内岩石露头存在两种类型的冲击角砾岩, 一 种是碎屑状角砾岩(图 4(a)), 另一种是部分熔融角砾 岩(图 4(b)). 碎屑状角砾岩直接覆盖在强烈破碎变形 的基岩之上, 角砾大小变化很大, 从几毫米到十多厘

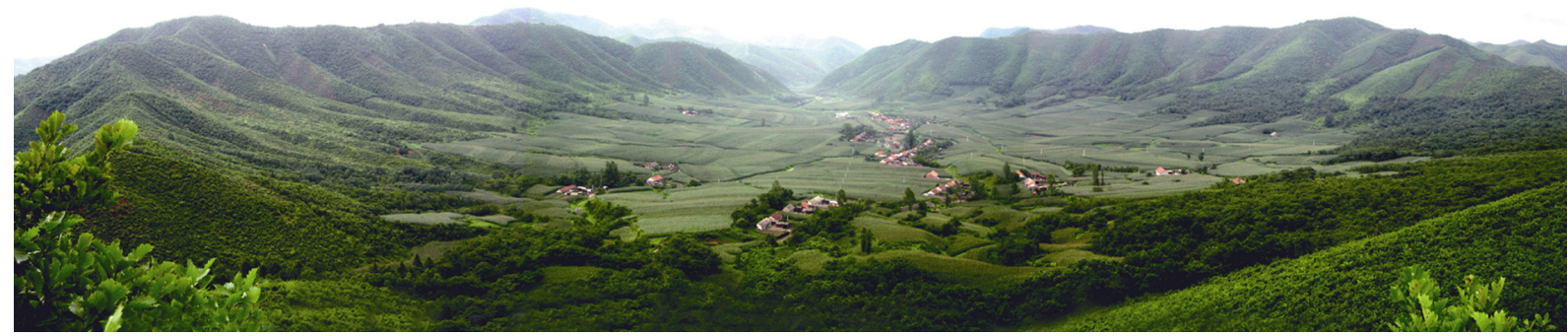

图 1 岫岩陨石撞击坑全景照片

该坑呈碗状形态, 坑唇北部(图左上方)和东部(图右上方)展示弧形坡地和放射状沟谷. 坑的底部覆盖较厚的第四系湖沼相沉积物. 整个坑区被小 灌木和庄稼等植被所覆盖

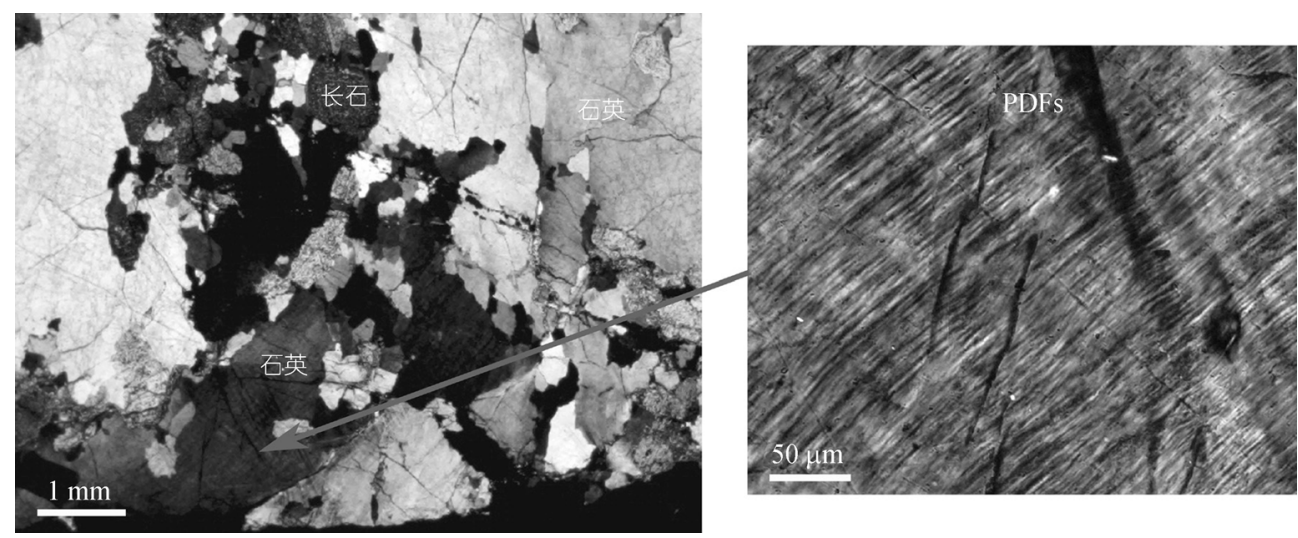

图 2 浅粒岩石英颗粒中存在的密集均匀的击变面状页理(PDFs) 石英颗粒中页理结构分布均匀, 非均质(白色层)与均质(灰色层)的片晶状薄片相间平行排列. 正交偏光

https:/lengine.scichina.com/doi/10.1360/csb2007-52-23-2777 


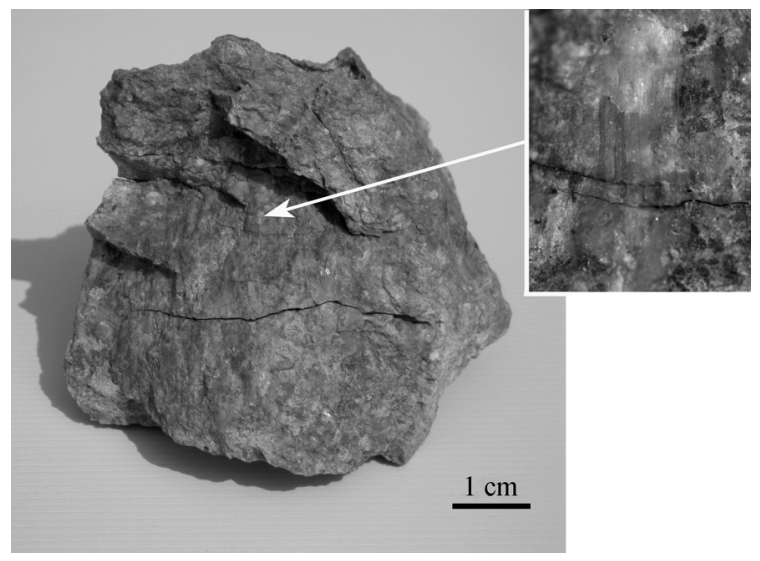

图 3 形成在浅粒岩中的震裂雉, 雉面上布满了擦痕状的 纵向沟槽

右上图表明在石英颗粒表面形成的沟槽

米不等, 岩石碎屑杂乱无章, 相对松散地堆积在一起. 部分熔融角砾岩的岩性较为致密, 呈透镜体状产出 在碎屑状角砾岩中，显示不规则的条带状或似流动 状构造, 岩石碎屑粒度一般小于 $5 \mathrm{~cm}$, 角砾含量约占 全岩的 40\%, 其余为部分熔融的基质物.

\section{4 放射状沟谷}

沿该环形构造北部和东部坑唇内侧坡地，形成 了许多向坑中心方向延伸的放射状沟谷(图 1), 相间 排列的放射状山梁和山谷形成了特殊的地貌特征. 许多沟谷延伸数百米从坑底部一直到坑唇顶部山脊, 在剖面上形成为舒展向上的弧形曲线. 这种特殊的 沟谷形态不同于一般的自然侵蚀风化形成的山梁和 山谷、火山口或其他地质地貌特征.

\section{3 讨论和结论}

所谓矿物击变面状页理, 是与冲击波作用有关,
产生在石英和长石等岛状和架状硅酸盐矿物中的一 种动高压变形微结构特征. 矿物击变面状页理通常 沿着晶体特定方向(如石英的 $\{10 \overline{1} n\})(n=1 \sim 4)$ 产生, 片晶状薄片在矿物中均匀分布平行排列, 单个薄片 厚度 $<1 \mu \mathrm{m}$. 石英中的击变面状页理可由以下微结构 组成: 高密度的位错带、不规则的石英微粒薄层、非 晶化玻璃薄层等 $[18,19]$. 除人工核爆炸和自然界大规 模撞击作用以外，任何其他地质作用包括火山喷发、 构造运动和地球深部高温高压等, 都不可能在矿物 中产生这种特殊的面状页理.

中国学者曾对太湖疑似陨石坑的石英颗粒变形 特征作过研究, 在其中发现了“变形纹”[4]或“微页 理”, [5], 并认为这些变形特征与冲击作用有关. 对比 相关资料显示, 太湖石英中存在的这类变形特征更 类似于一种面状裂隙(planar fractures, PFs), 与面状 页理(PDFs)有明显差别. 面状裂隙之间的宽度一般 大于 $5 \sim 10 \mu \mathrm{m}$, 分布不均匀, 平行于特定的晶体面, 如(0001)或 $\{1011\}$. PFs形成压力要远比PDFs低. 因此, $\mathrm{PFs}$ 不能作为冲击变质的结论性依据 ${ }^{[20]}$. 在中国报道 过的其他疑似陨石坑中, 尚没有石英和长石类矿物 冲击变形微结构特征的确切报道.

岫岩陨石撞击构造中发现的石英击变面状页理 特征十分典型, 其特征与世界上其他已知陨石撞击 坑中揭示的石英击变面状页理相同 ${ }^{[11,20 ~ 25]}$. 因此, 石 英颗粒中击变面状页理的发现, 为确定该坑陨石撞 击成因提供了确切证据.

岫岩陨石撞击构造呈现为典型的碗状坑，坑唇发 育, 整个形态保存较好, 属于简单坑. 坑内浅粒岩中震 裂雉的发现, 提供了岩石历经强烈冲击波作用的另一 证据 望。].坑唇内坡地发育的放射状沟谷，表明
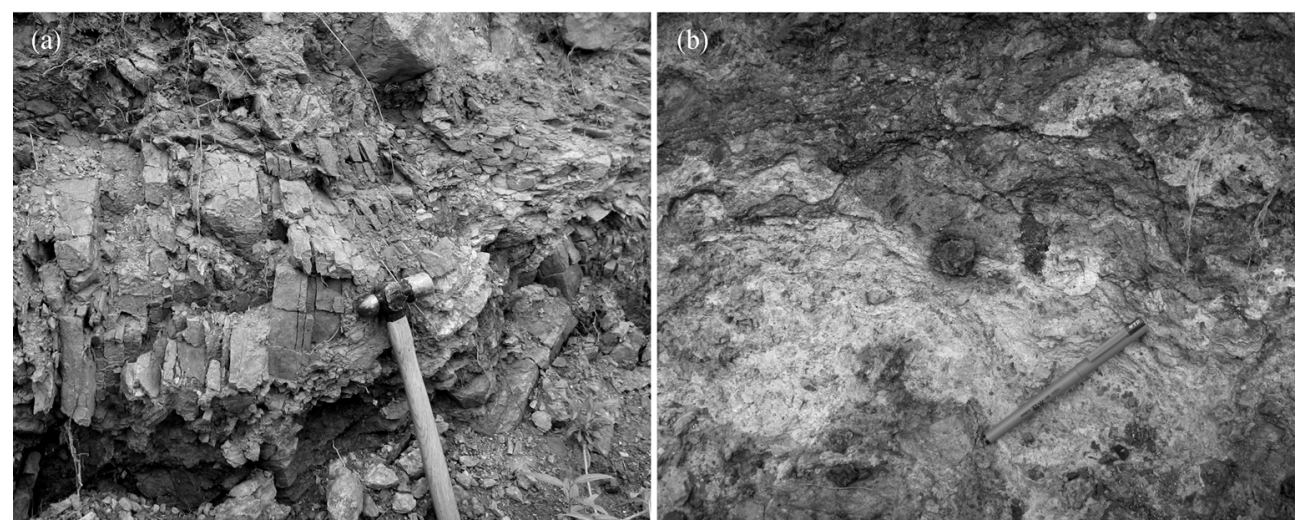

图 4 产出在陨石坑内的冲击角砾岩

（a）碎屑状角砾岩，显示相对松散的堆积; (b) 部分熔融角砾岩, 显示致密和不规则的似流动状构造, 岩石角砾分布在部分熔融的基质中 
了陨石超高速撞击导致坑内岩石向外抛射产生的特 殊地貌。坑唇和底部广泛发育的冲击角砾岩及其产 状表明了撞击作用导致靶区岩石发生破碎、变形、局 部熔融、飞浅和回落的撞击和成坑过程. 撞击成坑后, 该坑曾一度发育成为封闭的湖沼小盆地, 后因东北 方向坑唇形成缺口, 湖水流失.

岫岩坑是中国第一个被证实撞击起源的陨石撞 击坑，我们正对该坑进行系统的矿物冲击效应、坑体 结构、撞击年代、湖沼相沉积与古环境等研究, 以全 面揭示撞击坑的形成过程、特征和历史.

致谢 岫岩满族自治县人民政府对该项研究工作给予了支 持和配合, 付大鹏、齐经彦、李晓光、曹裕波协助了部分 野外工作, 特此一并致谢.

\section{参考文献}

1 Wu S. The Shanghewan impact crater, China. Lunar Planet Sci Conf, 1988, 19: 1296

2 Wu S. Geologic Feature of the Duolun Impact Crater, China. Lunar Planet Sci Conf, 1989, 20: 1219

3 傅成义. 太湖三山岛击变岩的发现及其意义. 地理学报, 1990, (2): $253-256$

4 何永年, 徐道一, 陆德复, 等. 太湖地区石英晶粒的冲击变形特 征一太湖成因初探. 科学通报, 1990, 35: 1163-1166

5 王尔康, 万玉秋, 施央申, 等. 太湖泽山岛冲击变质石英的发现 和意义. 科学通报, 1990, 38: 1875-1878

6 吴思本. 多伦陨石坑的研究进展. 中国地质, 1996, (8): 14-16

7 吴思本. 香港陨石坑的发现始末. 中国地质, 1997, (6): 48-49

8 王道经. 海南白沙陨石坑. 海口: 海南出版社, 1997

9 覃功炣, 卢登容, 欧强, 等. 罗圈里撞击坑铂族元素异常及粗铂 矿的发现及其意义. 地学前缘, 2001, 8(2): 333-338

10 赵树明. 在辽东半岛中部岫岩满族自治区内发现一撞击构造一一陨 石坑. 国土资源遥感, 2004, (3): 27

11 Chao E C T. Shock effects in certain rock-forming minerals. Science, 1967, 156: 192-202

12 French B M, Short N M. Shock Metamorphism of Natural Materials. Baltimore: Mono Book Corp, 1968

13 Stöffler D. Deformation and transformation of rock-forming minerals by natural and experimental shock processes: 1 . Behaviour of minerals under shock compression. Fortschr Miner, 1972, 49: 50-113
14 Stöffler D. Deformation and transformation of rock-forming minerals by natural and experimental processes: 2. Physical properties of shocked minerals. Fortschr Miner, 1974, 51: 256-289

15 Alexopoulos J S, Grieve R A F, Robertson P B. Microscopic lamellar deformation features in quartz: Discriminative characteristics of shock-generated varieties. Geology, 1988, 16: 796-799[DOI]

16 Sharpton V L, Grieve R A F. Meteorite impact, cryptoexplosion, and shock metamorphism: A perspective on the evidence at the $\mathrm{K} / \mathrm{T}$ boundary. In: Sharpton V L, Ward P D, eds. Global Catastrophes in Earth History, GSA Special Paper 247. Boulder: Geological Society of America, 1990. 301-318

17 Stöffler D, Langenhorst F. Shock metamorphism of quartz in nature and experiment: I. Basic observations and theory. Meteoritics, 1994, 29: 155-181

18 Xie X, Chao E C T. Studies on the lattice distortion and substructures of shock lamellae in naturally shocked quartz. Geochemistry, 1987, 6: 19-32

19 Goltrant O, Leroux H, Doukhan J C, et al. Formation mechanisms of planar deformation features in naturally shocked quartz. Phys Earth Planet Int, 1992, 74: 219-240[DOI]

20 Engelhardt W V, Bertsch W. Shock induced planar deformation structures in quartz from the Ries Crater, Germany. Contrib Miner Petrol, 1969, 20: 203-234

21 Therriault A M, Lindström M. Planar deformation features in quartz grains from the resurge deposit of the Lockne structure, Sweden. Meteoritics, 1995, 30: 700-703

22 Koeberl C, Reimold W U, Brandt D. Red Wing Creek structure, North Dakota: Petrographical and geochemical studies, and confirmation of impact origin. Meteorit Planet Sci, 1996, 31: 335342

23 Buchanan P C, Reimold W U. Planar deformation features and impact glass in inclusions from the Vredefort Granophyre, South Africa. Meteorit Planet Sci, 2002, 37: 807-822

24 Hough R M, Lee M R, Bevan A W R. Characterization and significance of shocked quartz from the Woodleigh impact structure, Western Australia. Meteorit Planet Sci, 2003, 38: 1341-1350

25 Reimold W U, Koeberl C, Hough R M, et al. Woodleigh impact structure, Australia: Shock petrography and geochemical studies. Meteorit Planet Sci, 2003, 38: 1109-1130

26 Dietz R S, McHone J F. Shatter cones: Definitive criteria for meteorite impact. Meteoritics, 1984, 19: 221 